\title{
A Escola de I Irau Noturno e o Compromisso com o Aluno Trabalhador
}

Pesquisadora: Maria Tereza Amaral Costa (Coordenadora), Maria Aparecida Lemos e Justina Inez Sponchiado

Instituição: Universidade do Estado de Santa Catarina

Fonte Financiadora: Instituto Nacional de Estudos e Pesquisas Educacionais (INEP)

O ensino noturno, desde o seu surgimento, que data dos anos 40 no Brasil, foi explicitamente "reservado ao trabalhador que estuda". Estudar à noite quase sempre significa enfrentar um terceiro turno de trabalho, se considerarmos o estudo como um trabalho intelectual, o que, em geral, não é levado em conta pelas políticas educacionais vigentes.

A pesquisa "A Realidade do Ensino de $\mathrm{I}^{\mathrm{o}}$ Grau Noturno no Município de Florianópolis", cujo relatório, elaborado em 1989, serviu para formular o presente texto, mostra que o aluno da escola pública noturna de $\mathrm{I}^{\mathrm{o}}$ grau é um menor trabalhador (faixa etária de 14 a 16 anos) que vai à escola em busca de melhores condições de vida.
Essa clientela se caracteriza como economicamente carente, se considerarmos que $63,3 \%$ dela percebe de um a dois salários mínimos mensais e que, inclusive, os alunos provêm de família cujos pais, na sua quase totalidade, não completaram o $\mathrm{I}^{\mathrm{o}}$ grau e exercem atividades profissionais consideradas de baixa renda. Essas famílias assim caracterizadas integram a classe trabalhadora.

Levando-se em conta o progressivo empobrecimento da classe trabalhadora, verificamos que há cada vez mais a incorporação precoce dos membros dessas famílias no mercado de trabalho. A clientela do ensino noturno, embora iniciante, já vem contribuindo com a 
sociedade à qual pertence. Esses jovens trabalhadores, que chegam à escola noturna em precárias condições físicas e intelectuais (cansados e mal alimentados), desafiando o seu potencial, também nos desafiam para uma reflexão mais profunda sobre a escola que os recebe.

Nesse sentido, citamos Caporalini (1991, p.32-33):

"Tem-se que optar entre continuar tratando o estudante que trabalha como um carente crónico que precisa ser alimentado, informado, integrado, educado sob formas compensatórias e paliativas, ou passar a tratá-lo como um cidadão trabalhador historicamente excluído dos direitos básicos que, através de uma educação de boa qualidade, precisa tomar consciência dessa exclusão e se organizar na reivindicação de seus direitos".

Então nos deparamos com o seguinte questionamento: como uma escola caracteriza o que é qualidade?

Pensamos que a questão da qualidade passa necessariamente pela adequação do currículo, o que corresponde aos anseios e expectativas da clientela da escola noturna. Sabe-se que o planejamento curricular em termos de escola não leva em conta essa questão; a escola noturna continua existindo como extensão da escola diurna. Segundo Célia P. Carvalho (1987), "...continua-se a planejar apenas em função da demanda diurna". Entretanto, na prática da escola, existe um tratamento diferenciado a esses alunos. Segundo depoimento de $58,7 \%$ dos professores, na avaliação do rendimento escolar, há maior tolerância com o aluno dos cursos noturnos. Sobre essa questão, os professores da amostra assim se posicionaram:

"Há menor cobrança e mais tolerância, pois os alunos se dizem esgotados, com fome, e, por isso, indispostos par trabalhar."

"Eles têm menos tempo ou quase nenhum para se preparar para as provas."

"O conteúdo é dado de maneira mais simples para que o aluno possa assimilar o mínimo exigido." 
"Como esses alunos já atuam em outras atividades nos outros períodos, não se pode dar a mesma carga de trabalho."

A pesquisa evidenciou que a prática da escola noturna não está centrada na realidade do aluno, visto que não há um posicionamento em relação à questão do trabalho.

A escola finge que faz esse direcionamento ao oferecer a disciplina "Preparação para o Trabalho". Observem-se as colocações feitas pelos alunos, quando se referem à forma como vem sendo trabalhada essa disciplina: "não é condizente com a nossa realidade"; "não interessa"; "não é importante"; "não traz muita coisa para o dia-a-dia".

A escola noturna comprometida com o aluno trabalhador deveria organizar sua prática, possibilitando a compreensão do papel do trabalho na sociedade e o conhecimento da importância social de determinados tipos de trabalho. Segundo Neidson Rodrigues (1987, p.60), a escola deveria levar o aluno trabalhador a "...entender o sentido da marginalização económica - que aproveita o trabalho do pedreiro, do cortador de papel, do lavrador, pois incorpora a sua produção às riquezas nacionais, sem ao mesmo tempo valorizar o trabalho que as produz".

A discussão da prática da escola noturna, durante o três seminários ${ }^{1}$ realizados, partindo dos professores de uma das escolas, resultou em propostas, assim formuladas:

"Que seja feita pelos professores de $\mathrm{I}^{\mathrm{O}}$ grau noturno uma análise crítica da sua prática docente, buscando, desta forma, aprimorá-la e defini-la de acordo com sua postura ideológica e filosófica."

"Que o professor de $\mathrm{I}^{\mathrm{O}}$ grau noturno analise, conjuntamente com seus colegas e com pessoas competentes, constantemente, sua prática pedagógica na escola."

Segundo Caporalini (1991), a prática escolar diferenciada, revela-

\footnotetext{
${ }^{1}$ Os resultados da pesquisa foram discutidos em três seminários sobre o ensino de $\mathrm{I}^{\circ}$ grau noturno, do qual parti cipou a comunidade escolar envolvida na pesquisa (alunos, professores, técnicos administrativos e representantes da Secretaria da Educação) Foi elaborado um documenlo-síntese dos três seminários, contendo propostas de melhoria para o ensino noturno.
} 
da nos estudos sobre a escola noturna, mostra que os professores que trabalham com as camadas populares ministram, em geral, um ensino empobrecido, o que concorre para aumentar os índices de evasão e repetência.

A pesquisa mostrou um número elevado de alunos evadidos. Observe-se que a matrícula inicial nas escolas pesquisadas era de 890 alunos (em março de 1987) e, por ocasião da coleta de dados, ocorrida entre 10/09/87 e 11/11/87, o número de alunos que frequentavam o ensino de $\mathrm{I}^{\mathrm{O}}$ grau noturno era de 488.

Silva (1984), ao analisar a questão da reprovação e da tendência do aligeiramento do ensino, assim se expressa: "...de um lado, há os jovens que são reprovados e acabam saindo da escola; de outro, os jovens que ficam na escola, mas recebem um ensino inferior, e, sem conteúdos significativos, conteúdos relevantes, a escola se transforma num arremedo, numa farsa".

Rodrigues (1987), num estudo realizado com exluídos-evadidos do ensino de $\mathrm{I}^{\mathrm{O}}$ grau noturno, afirma que: "...a escola em nada contribui para que o alunos permaneçam estudando e trabalhando. Pelo contrário, através de sua estrutura e, pela sua dinâmica interna, cinde a unidade aluno-trabalhador, negando este último".

A afirmação da autora assume maior importância quando se analisam alguns aspectos revelados pela pesquisa, como por exemplo a rotina do aluno que trabalha, que dorme tarde, acorda cedo, alimenta-se mal, trabalha mais de oito horas por dia, chega à escola em precárias condições físicas e intelectuais e encontra uma sala de aula pouco motivadora devido à precariedade de recursos didáticos e à metodologia desestimulante, pois também o professor, quase sempre, está enfrentando um terceiro turno de trabalho.

Os professores, durante a realização dos referidos seminários, apontaram para a necessidade de "uma transformação no sistema educacional vigente", na questão da política educacional. No que se refere a essa transformação do sistema de ensino, apontada pelos professores, constata-se que a Secretaria da Educação preocupou-se apenas em expandir o ensino noturno. 
Muito provavelmente, essa expansão decorreu da ação da Comissão Permanente para Assuntos Ligados ao $\mathrm{I}^{\mathrm{o}}$ Grau Noturno ${ }^{2}$, quando propôs emenda à Constituição Estadual, garantindo o ensino noturno regular na rede pública estadual, adequado às condições do aluno e sem perder de vista a sua educação integral.

Assim, a partir de 1987, quando da execução da pesquisa, o número de escolas públicas da rede estadual que atendem ao $\mathrm{I}^{\mathrm{o}}$ grau noturno passou de sete para 18 escolas, segundo dados de 1991, fornecidos pela Secretaria da Educação.

Questiona-se: estarão essas escolas atendendo às necessidades do aluno que trabalha, ou estão a lhe oferecer somente o horário noturno? Quando se enfatiza a importância da democratização da educação, implicitamente depara-se com a questão dos direitos do cidadão que frequenta a escola noturna.
Desta forma, uma escola que se destina a atender às necessidades da classe trabalhadora terá que assumir suas finalidades sociais, o que significa reafirmar a necessidade de um projeto de educação escolar, gerado nesta sociedade, onde as condições concretas de vida dos alunos e sua destinação se constituem o ponto fundamental.

Assim, concluímos com os seguintes questionamentos:

- Estamos conscientes de que, ao buscar o ensino de $\mathrm{I}^{\mathrm{o}}$ grau noturno, o aluno já foi lesado nos seus direitos como cidadão?

- Qual a responsabilidade da sociedade que explora o menor trabalhador que contribui para a produção do capital, mas que recebe uma escola que não atende às suas necessidades?

- Qual, então, a responsabilidade dessa sociedade, quando proclama a igualdade de oportunidade?

\footnotetext{
${ }^{2}$ A referida comissão foi formada por pesquisadores, professores e alunos das escolas que fizeram parte da pesquisa. A necessidade de se compor a referida comissão surgiu durante o $3^{\circ}$ Seminário sobre o Ensino de $\mathrm{I}^{\circ}$ Grau Noturno, e teve como objetivos a elaboração de um documenlo-síntese dos três seminários como também a elaboração e a apresentação da Proposta de Emenda Aditada à Assembleia Legislativa, por ocasião da elaboração da Constituição Estadual, visando respaldar no plano constitucional, em Santa Catarina, o ensino noturno.
} 


\section{Referências Bibliográficas}

CAPORALINI, Maria Bernadete Santa Cecília. A transmissão do conhecimento e o ensino notumo. Campinas: Papirus, 1991.

CARVALHO, Célia Pczzolo de. Ensino notumo - realidade e ilusão. São Paulo: Cortez: Autores Associados, 1986.

RODRIGUES, Ana Tereza Drumond. Ou bem estuda ou bem trabalha: a relação escola trabalho a partir da representação do aluno excluído-evadido. Belo Horizonte, 1987. Dissertação (Mestrado em Educação) - UFMG.

RODRIGUES, Neidson. Da mistificação da escola à escola necessário. São Paulo: Cortez: Autores Associados, 1987.

SILVA, Tereza Roseley N NOGUEIRA, Madza Julita. À escola pública e o desafio do curso notumo. São Paulo: Cortez: Autores Associados, 1984. 